\title{
Avaliação das propriedades do Resíduo da Cons- trução Civil RCC como subsídio para confecção de tijolos de solo-cimento.
}

Silva, L. A. S.

Escola Politécnica de Pernambuco

Universidade de Pernambuco

50.720-001 - Recife, Brasil

laize.civil.upe@gmail.com

\author{
Lafayette, K. P. V. \\ Escola Politécnica de Pernambuco \\ Universidade de Pernambuco \\ 50.720-001 - Recife, Brasil \\ klafayette@poli.br
}

Resumo A construção civil é geradora de grande volume de resíduos da construção civil (RCC). A destinação de RCC em locais inadequados provoca impactos ambientais prejudiciais. Buscam-se alternativas sustentáveis para a reintrodução dos RCC na indústria da construção. Dentro desse seguimento, a presente pesquisa visa avaliar a possibilidade técnica do uso de RCC em tijolos prensados de solo-cimento. A metodologia consiste na coleta de solo e resíduo para a obtenção das características fisicas e do comportamento mecânico de composições de solo-cimento e solocimento com adição de $25 \%$, 50\% e 75\% de RCC. Foram alcançados resultados satisfatórios para a mistura com $25 \%$ de resíduo, comprovando que é possivel a utilização desse material em tijolos de solo-cimento.

\footnotetext{
Abstract The civil construction is a generator of a huge amount of waste of civil construction (WCC). The destination of WCC in inappropriate places causes environmental impacts which are harmful. Sustainable alternatives have been sought to reintroduce WCC in the construction industry. Within this segment, the following research aims to evaluate the technical possibility of using WCC in pressed bricks of soil-cement. The methodology consists in gathering soil and waste to obtain the physics characteristics and mechanics behavior of compositions of soil-cement and soil-cement in addiction with $25 \%, 50 \%$ and $75 \%$ of WCC. Satisfactory results were obtained for the mixture with $25 \%$ of waste, proving that it is possible to use this material in bricks of soilcement.
} 


\section{Introdução}

Tendo em vista a busca do desenvolvimento sustentável, estudos têm sido realizados para que os resíduos da construção civil (RCC) possam ser reaproveitados de forma adequada, obtendo-se vantagens técnicas e menores custos. Desta maneira, os impactos ambientais produzidos pelos materiais descartados, muitas vezes de forma inadequada, são reduzidos e, eventualmente, passam a não mais existir.

Uma das aplicações dos RCC é em tijolos de solo-cimento, objetivo desta pesquisa. Em sua maioria, os resíduos são constituídos por cerâmicos, restos de argamassa e concreto, o que possibilita sua reciclagem.

A introdução de RCC na fabricação de tijolos de solocimento pode ser ideal para proporcionar ao solo utilizado características adequadas para seu uso. Além disso, o teor de cimento pode ser reduzido, mantendo-se a resistência à compressão especificada nas normas [1].

\section{Materiais e Métodos}

\subsection{Solo}

O solo utilizado foi coletado em uma área de encosta com alto grau de erosão, situada no Cabo de Santo Agostinho (RMR). Foram coletadas amostras deformadas a $2,5 \mathrm{~m}$ de profundidade, totalizando cerca de $210 \mathrm{~kg}$ de solo.

\subsection{Resíduo de construção civil}

O RCC foi coletado na Usina de Beneficiamento Ciclo Ambiental, localizada em Camaragibe (RMR). Foi feita a coleta de cerca de $280 \mathrm{~kg}$ de resíduo misto.

\subsection{Cimento}

Utilizou-se um cimento CPII-E 32. Foi adotado um teor de $7 \%$ de cimento em relação da massa de solo devido a recomendações da Associação Brasileira de Cimento Portland (ABCP), com base na classificação H.R.B. (Highway Research Board) do solo.

\subsection{Caracterização física}

\subsubsection{Composição Granulometrica}

Os ensaios de análise granulométrica foram realizados de acordo com a NBR 7181 [2]. Foi analisada a granulometria do solo, do resíduo e misturas dos dois materiais com teores de $10 \%, 25 \%, 50 \%$ e $75 \%$ de RCC.

\subsubsection{Compactação}

Os ensaios de compactação foram executados segundo a norma NBR 7182 [3]. Através destes, foram obtidas as umidades ótimas e peso específico aparente seco máximo.

A umidade ótima é um importante parâmetro nos trabalhos realizados com solo por permitir condições melhores de máxima compactação do material, dando a este maior resistência, densidade e durabilidade [4].

Foram feitos ensaios de compactação do solo, do resíduo e das composições contendo $10 \%, 25 \%, 50 \%$ e $75 \%$ de RCC.

\subsection{Compressão Simples}

\subsubsection{Corpos de Prova Cilíndricos}

Os ensaios de compressão simples foram realizados com teores de $25 \%, 50 \%$ e $75 \%$ de RCC, seguindo a norma NBR 12025 [5]. A moldagem dos corpos de prova cilíndricos foi realizada conforme a NBR 12024 [6], utilizando-se da energia Proctor Normal.

Moldaram-se seis corpos-de-prova para cada traço; três rompidos aos 7 dias e três ao 28 dias.

Para a realização dos ensaios de compressão, utilizouse uma prensa Emic, modelo 30.000.

\section{Apresentação e Análise dos Resulta- dos}

\subsection{Caracterização Física}

\subsubsection{Composição Granulométrica}

Através dos ensaios de peneiramento e sedimentação, obtiveram-se as curvas granulométricas do solo, do resíduo e misturas, mostradas na Fig. 1.

De acordo com a classificação trilinear dos solos, o solo estudado é areno argiloso. O RCC, em sua grande maioria apresenta frações de areia. 


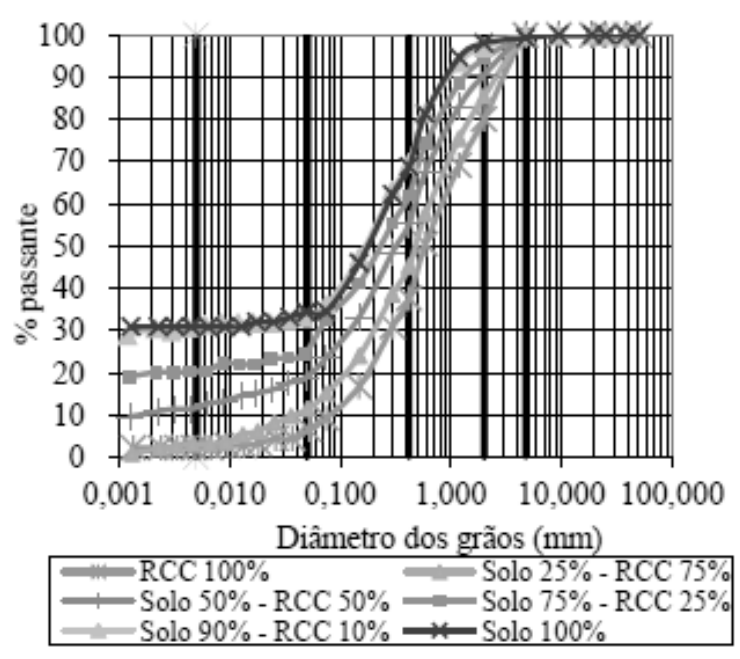

Fig. 1. Curvas Granulométricas.

\subsubsection{Comptactação}

A Fig. 2 mostra as curvas obtidas através dos ensaios de compactação aplicando-se energia de Proctor Normal.

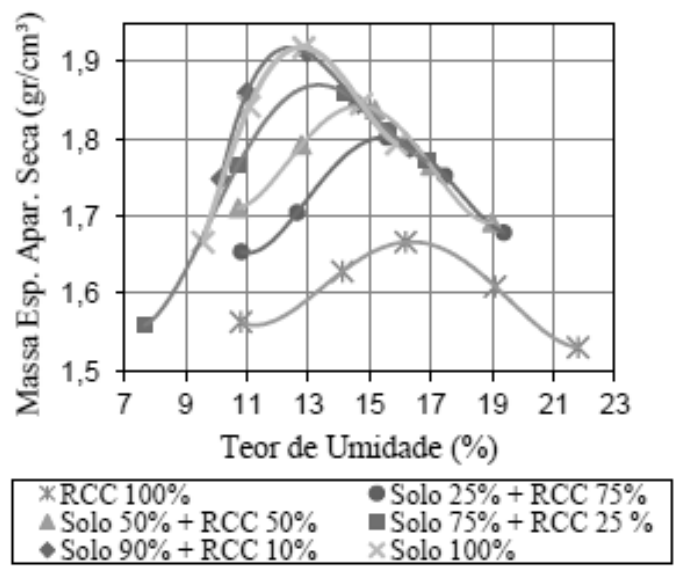

Fig. 2. Curvas de compactação.

Nota-se que com o aumento do teor de RCC, a umidade ótima aumenta, enquanto que o peso específico seco máximo diminui.

\subsection{Compressão Simples}

A ABNT - NBR 8491 especifica que a resistência à compressão da média de tijolos maciços não deve ser inferior a 2,0 $\mathrm{MPa}$ com idade mínima de sete dias. Em pesquisas anteriores, é notável o acréscimo de resistência de composições de solo-cimento e resíduo com o passar do tempo [1].

\subsubsection{Corpos de prova cilíndricos}

A Fig. 3 apresenta os resultados obtidos nos ensaios de resistência à compressão dos corpos-de-prova cilíndricos, com 7 e 28 dias de cura.

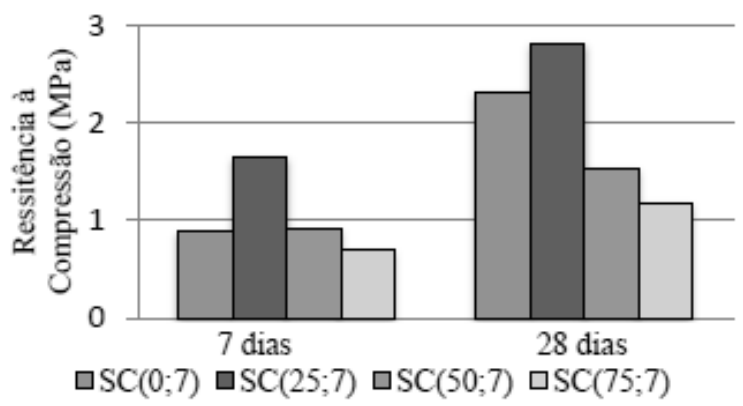

Fig. 3. Resultados de resistência à compressão dos corpos-de-prova cilindricos.

Sendo SC(R;C) a denominação dos traços de solo-cimento; R: resíduo; C: cimento.

A Tabela 1 mostra dos valores de tensão máxima alcançada para cada estudada, com respectivo acréscimo de resistência em porcentagem.

Tabela 1. Valores de resistência à compressão dos corpos-de-prova cilindricos.

\begin{tabular}{|c|c|c|c|}
\hline $\begin{array}{l}\text { Traço } \\
\mathrm{S}_{(\mathrm{R}, \mathrm{C})}\end{array}$ & $\begin{array}{c}\text { Resistência } \\
\text { à } \\
\text { compressão } \\
7 \text { dias } \\
(\mathrm{MPa}) \\
\end{array}$ & $\begin{array}{c}\text { Resistência } \\
\text { à } \\
\text { compressão } \\
28 \text { dias } \\
(\mathrm{MPa})\end{array}$ & $\begin{array}{c}\text { Acréscimo } \\
\text { de } \\
\text { resistência } \\
(\%)\end{array}$ \\
\hline $\mathrm{SC}_{(0 ; 7)}$ & 0,89 & 2,31 & 61,47 \\
\hline $\mathrm{SC}_{(25 ; 7)}$ & 1,66 & 2,82 & 41,13 \\
\hline $\mathrm{SC}_{(50 ; 7)}$ & 0,92 & 1,53 & 39,87 \\
\hline $\mathrm{SC}_{(75 ; 7)}$ & 0,70 & 1,18 & 40,68 \\
\hline
\end{tabular}

É notável que o melhor traço de solo-cimento e resíduo analisado é o que possui $25 \%$ de RCC e $7 \%$ de cimento em relação à massa de solo, por proporcionar melhores resultados. Traços com percentual superior a $25 \%$ resultam em misturas com um baixo teor de aglomerantes, assim, não têm coesão suficiente para garantir resistência a tais composições.

Para a resistência ideal determinada pela NBR 8491 [7], os traços $\mathrm{SC}_{(0 ; 7)}$ e $\mathrm{SC}_{(25 ; 7)}$ analisados apresentaram resultados satisfatórios aos 28 dias. 


\section{Conclusões}

1. De acordo com a curva granulométrica e os limites de consistência o solo foi classificado como um A2-6, pela H.R.B., ou seja, uma areia argilosa;

2. Quanto maior a porcentagem de RCC, maior a umidade ótima e menor a massa específica aparente seca máxima do material;

3. O traço com $\mathrm{SC}(25,7)$ foi o que apresentou melhor desempenho dentre as composições estudadas, tanto por atingir resistência superior a 2,0 Mpa aos 28 dias;

4. Para porcentagens acima de $25 \%$ de RCC, a mistura de solo-cimento-resíduo tornou-se muito arenosa, com pouca porcentagem de aglomerantes, dessa forma, não foi obtida resistência adequada.

\section{Referências}

[1] FERRAZ, André Luiz Nonato. Análise da adição de resíduos de argamassa de cimento em tijolos prensados de solo-cimento. 2004. 114 f. Dissertação (Mestrado) - Universidade Estadual Paulista, Ilha Solteira.

[2] Associação Brasileira de Normas Técnicas ABNT. NBR 7181: Solo - Análise Granulométrica - Procedimento. Rio de Janeiro, 1984.

[3] Associação Brasileira de Normas Técnicas ABNT. NBR 7182: Solo - Ensaio de Compactação - Procedimento. Rio de Janeiro, 1986.

[4] Associação Brasileira de Normas Técnicas ABNT. SOUZA, Márcia I. B.; SEGANTINI, Antonio A. S.; PEREIRA, Joelma A.. Tijolos prensados de solo-cimento confeccionados com resíduo de concreto. Revista Brasileira de Engenharia Agrícola e Ambiental, Campina Grande, v. 12, n. 2, p.205-212, 18 set. 2007.

[5] Associação Brasileira de Normas Técnicas ABNT. NBR 12025: Solo-cimento - Ensaio de compressão simples de corpos-de-prova cilíndricos - Método de ensaio. Rio de Janeiro, 1990.

[6] Associação Brasileira de Normas Técnicas ABNT. NBR 12024: Solo-cimento - Moldagem e cura de corpos-de-prova cilíndricos - Método de ensaio. Rio de Janeiro, 1992.

[7] Associação Brasileira de Normas Técnicas -
ABNT. NBR 8491: Tijolo maciço de solo-cimento - Especificação. Rio de Janeiro, 1984. 